\title{
DE ANZUELOS Y ESPEJOS O CÓMO ENCONTRAR LA SALIDA AL LABERINTO DE LA ALIENACIÓN
}

\author{
Esther Claudio \\ estherclaudio@g.ucla.edu \\ University of California
}

Recibido: 02-10-2016

Aceptado: 30-04-2017

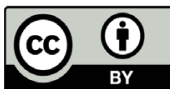

RESUMEN

En El Martin Pescador, Luis Durán crea un interesante universo onírico que reflexiona acerca del poder, la identidad, la infancia y los recuerdos. En este artículo exploro el tema de la alienación a través del estudio del espejo y del laberinto como tropos literarios. Partimos de un estudio lacaniano de la alienación como carencia, la cual coloca al héroe en la situación de bienes limitados que impulsa su viaje. A través del análisis de los rasgos formales, el simbolismo y la intertextualidad de El Martín Pescador se proponen tres tipos de laberintos como reflejo de la travesía del héroe por la ciudad. Esta lectura sugiere finalmente que la alienación de Martín se resuelve al adquirir un lenguaje metafórico facilitado por su travesía por el mundo onírico.

Palabras Clave: alienación, laberinto, espejo, Lacan, infancia, identidad, onírico.

\section{SUMMARY}

In El Martin Pescador, Luis Durán creates an interesting oneiric universe that reflects on power, identity, childhood and memories. In this article, I explore the topic of alienation through the study of the mirror and the maze as literary tropes. We start from a Lacanian study of alienation as lack, which places the hero in a limited goods situation that triggers his journey. Through the analysis of formal features, symbolism and intertextuality in El Martin Pescador, I propose three types of mazes as a reflection of the hero's itinerary within the city. This reading finally suggests that Martin's alienation is solved by acquiring a metaphorical language provided by his journey through the oneiric world.

KEYWORDS: alienation, maze, mirror, Lacan, childhood, identity, oneiric. 
Lo fantástico es una grieta o una dislocación en lo cotidiano que va más allá de la mera desfamiliarización, es una continua sorpresa ante la alteración de lo conocido. El Martín Pescador de Luis Durán utiliza el mundo onírico para invadir y desfigurar la lógica de la vigilia. El mundo de los sueños se cuela por las rendijas de la existencia diurna y ofrece una nueva manera de articular la realidad. La obra es un fructífero diálogo entre el surrealismo y lo fantástico que confluyen en la epifanía del héroe.

La alienación es un tópico recurrente en el género fantástico dado que la mayoría de obras constituyen, en mayor o menor medida, una reconstrucción de la identidad del protagonista. El Martín Pescador no es una excepción, pero su fecunda exploración del espejo como tropo literario proporciona una interesante reflexión en torno a este tema. Asimismo, el laberinto como viaje del héroe adquiere aquí una serie de connotaciones simbólicas que no solo expresan gráficamente una desorientación y dificultad intrínsecas a este tipo de estructura, sino que establece un interesante diálogo con el folclor y lo fantástico. Con la mirada puesta en el tema de la alienación, en el tropo del laberinto y tomando la antropología literaria como base, nuestra lectura explora los rasgos formales y el simbolismo de El Martín Pescador. Consideramos que la obra conjuga lo fantástico y lo surrealista para perseguir, como propuso André Bretón en el Primer Manifiesto Surrealista, «la armonización de estos dos estados, aparentemente tan contradictorios, que son el sueño y la realidad, en una especie de realidad absoluta, en una sobrerrealidad o surrealidad, si así se le puede llamar» (1969: 30).

\section{LUIS DURÁN Y EL MARTÍN PESCADOR: UNA TRAVESÍA POR LOS SUEÑOS ${ }^{1}$}

En una entrevista con Jesús Jiménez, Luis Durán comenta su admiración por los «gnósticos, neoplatónicos, románticos, renacentistas, alquimistas y poetas, [quienes] dejaron de lado el racionalismo cartesiano y se atrevieron a observar el cosmos de otra manera, desde otro prisma más metafórico y simbólico y también menos literal del que, por lo general, utilizamos en los tiempos actuales» (Durán, 2014). Sus obras son un diálogo entre el orden conocido y la alteración subversiva y evocadora del mismo. Los personajes que

1. Sobre la trayectoria del autor recomendamos consultar su propia web, http://www.luisdurancomic. $\mathrm{com} /$, además de otras páginas dedicadas al estudio del cómic y la novela gráfica como La guía del cómic (http://laguiadelcomic.blogspot.com/), Entrecomics (http://www.entrecomicscomics.com/) o Trazos en el bloc (http:/ / trazosenelbloc.blogspot.com.es/), que incluyen información actualizada y entrevistas con Durán. 
pueblan estos espacios a menudo se quejan «de que hemos literalizado todo y de que hemos confundido el mapa con el territorio» (Durán, 2014) y la jerarquía diegética así como la ontología de todos los mundos posibles se ponen en entredicho en el universo expresionista de Durán.

Sus guiones, varias veces premiados tanto en España como en Francia, entretejen con paciencia una compleja red de referencias y símbolos. Una forma de narrar depurada a lo largo de décadas que se deleita en la participación del lector implícito para completar los «espacios de indeterminación». ${ }^{2}$ Así, la lectura se convierte en un proceso conjunto, cuyo significado se negocia en cada viñeta, y se erige sobre el uso de la metáfora en un juego casi surrealista de libre asociación de ideas.

La trayectoria de Luis Durán ha sido intermitente pero ascendente. En los años 90 publica pequeños trabajos en numerosos fanzines y prensa local (Diario Vasco, El Correo Español y Diario de Burgos) pero no obtiene el respaldo del público y decide centrarse en ilustraciones y colaboraciones para publicaciones infantiles. A finales de la década, en 1999, autoedita Solsticio, su primera novela gráfica, lo que le proporciona el reconocimiento de crítica y público. Desde entonces, el mercado acoge una de sus obras casi cada año y su trabajo es una superación constante.

El Martín Pescador fue publicado en 2007 y es una de sus novelas gráficas más reconocidas. Durán tiene un estilo pictórico fácilmente reconocible por el tono expresionista, el uso de claroscuros y las siluetas alargadas y geométricas. Como en El Martín Pescador, normalmente suele utilizar el blanco y negro, aunque a veces publique a color, caso de su última obra, Orlando y el juego, que recupera personajes aparecidos por primera vez en El Martín Pescador, como Tutumukuku.

El Martín Pescador es la historia de Martín, un escritor y profesor de literatura en la Universidad que recibe el encargo de escribir la biografía de un político también llamado Martín, en este caso, Martín Altán. Esta biografía es un tanto peculiar porque el político no compartiría sus recuerdos, sino que propone comprar los de Martín y que la vida del escritor se venda como la del político. El protagonista acepta el trabajo, pero le provoca una fuerte crisis de identidad que le mueve a iniciar una búsqueda personal y moral. En su cami-

2. El propio Durán afirma que «El papel del lector es fundamental —asegura Luis— siempre está al final del proceso creativo que conlleva hacer un libro. Sin un lector todo lo escrito se quedaría en cierto modo incompleto. Probablemente existan tantos libros como lectores. O, tal vez habría que llamarles coautores ya que, al abordar las historias desde otra perspectiva distinta a la del autor, aportan siempre algo nuevo al libro» (Durán, 2012a). 
no le acompaña Arearea, una extraña niña, muy madura, que trabaja para Altán pero se alía con Martín para huir del entorno del político. Ella es un personaje obsesionado con los espejos, que lee la biografía de Martín como un reflejo de sí misma y le ayuda a reconocer el peligro de que el político se quede con sus recuerdos. Mientras, el protagonista tiene extraños sueños en que su vecino, Tutumukuku, trata por todos los medios de comunicarse con él. Un día, éste se presenta en su casa con su amiga Aurelia y le explica que tiene una ONG onírica para socorrer a la gente mientras duerme pero que no encuentra un canal de comunicación con él. Martín le pide un espejo en que poder mirarse y reconocerse a sí mismo. Tutu entonces se vuelve a introducir en sus sueños y le muestra la manera de poner fin al abusivo encargo del político que lo tenía absolutamente alienado.

\section{EL ESPEJO QUE CARECE DE REFLEJO: LA ALIENACIÓN}

Para Jaques Lacan, el sujeto toma conciencia de sí mismo en la fase del espejo, cuando la mirada del doble (del reflejo) se convierte en la mirada del otro, transformando al que mira en sujeto: «L'assomption jubilatoire de son image spéculaire par l'être ... nous paraîtra dès lors manifester en une situation exemplaire la matrice symbolique où le je se précipite en une forme primordiale, avant qu'il ne s'objective dans la dialectique de l'identification à l'autre» (1966: 90). La identificación de uno mismo ante el espejo es la misma operación que después lleva a reconocer la proyección que otros hacen del sujeto. La identidad se forma en sociedad, a través de los reflejos que los demás devuelven de uno. Cuando esos reflejos no se corresponden con la imagen propia, el desasosiego conduce a la alienación.

Lacan (2006) también define la alienación como una forma de carencia. Convertirse en sujeto implica escindirse del cuerpo de la madre literal y simbólicamente. Como Freud, Lacan considera que el niño lactante toma a la madre y al mundo como extensiones narcisistas de sí mismo. La función (simbólica) del padre (o de la figura que ejerza como tal) es la de escindirlo del exterior, separarlo para verse a sí mismo como un sujeto diferente del resto. Esa figura castrante le devuelve la mirada del espejo y el sujeto toma conciencia de ser un yo menos el mundo, un yo en permanente carencia de la unión con la madre y el entorno. Lacan explica la alienación como ausencia a través de la teoría de conjuntos, en concreto de diagramas de Venn, cuya expresión matemática se repite a lo largo del cómic tanto en la exposición artística que visitan Arearea y Martín como en las imágenes que acompañan las palabras de despedida de la niña. 
Esta doble vertiente de la alienación se expresa gráficamente en El Martín pescador a través de dos objetos simbólicos, el espejo y el laberinto. Martín, el protagonista, se aliena al asomarse como en un espejo al siniestro mundo del político Martín Altán y la carencia de una infancia, de un reflejo propio, es el impulso para recorrer el laberinto que lo lleva hasta el mundo fantástico de lo onírico.

\section{Martín / Altán: FAusto frente Al EsPejo}

Cuando Martín recibe un día la visita de dos hombres que lo recogen para entrevistarse con el político Martín Altán, se adentra, como un Fausto moderno, en un universo sombrío donde nada es lo que parece: la familia del político son actores, su lugar de residencia es un misterio, su discurso contradice sus actos y cada pequeño gesto es una forma de ocultar la verdad. A mantener esta entelequia contribuye la biografía inventada de Martín, quien vende sus recuerdos en este nuevo orden dionisíaco.

Martín y Martín Altán son imágenes especulares opuestas. Mientras Martín es un modesto escritor, Altán es el estereotipo de político malvado y perverso. La figura vampírica de Altán se personifica en la madrastra de Blancanieves. En el capítulo «los dos lados del espejo», ${ }^{3}$ Martín comienza a redactar los recuerdos de su niñez con su abuelo el pescador y mientras describe cómo observa «toda una cacharrada de cubiertos y anzuelos pender de las paredes» (Fig. 1), las viñetas muestran a la malvada madrastra avanzar por el palacio hasta acercarse a coger el espejo mágico. En la siguiente página se recuperan las imágenes del abuelo que anima al pequeño Martín a ir con él a pescar hasta que la voz narrativa dice «la persona a la que habla soy yo. Me llamo Martín Altán» (Fig. 2) en dos viñetas consecutivas que de nuevo recuperan a la madrastra, esta vez observando su reflejo. Los anzuelos que menciona se entremezclan con las imágenes de la madrastra para indicar que Martín «ha mordido el cebo» y la figura vampírica del político, gráficamente expresado en forma de madrastra de Blancanieves, succiona su niñez y su identidad.

El efecto del vampirismo es la reificación marxista. Su alienación nace de un tipo de trabajo que lo reduce a cosa: «Lamenté haber aceptado aquel trabajo que comenzaba a enfermarme» dice Martín «y me sentí como el reflejo de algo deforme» (90-91). No le ocurre así en su verdadero oficio de profesor de literatura en la universidad, que desarrolla a diario sin dilemas. Es la venta de sus

3. A partir de ahora siempre citaré por Durán (2007). 


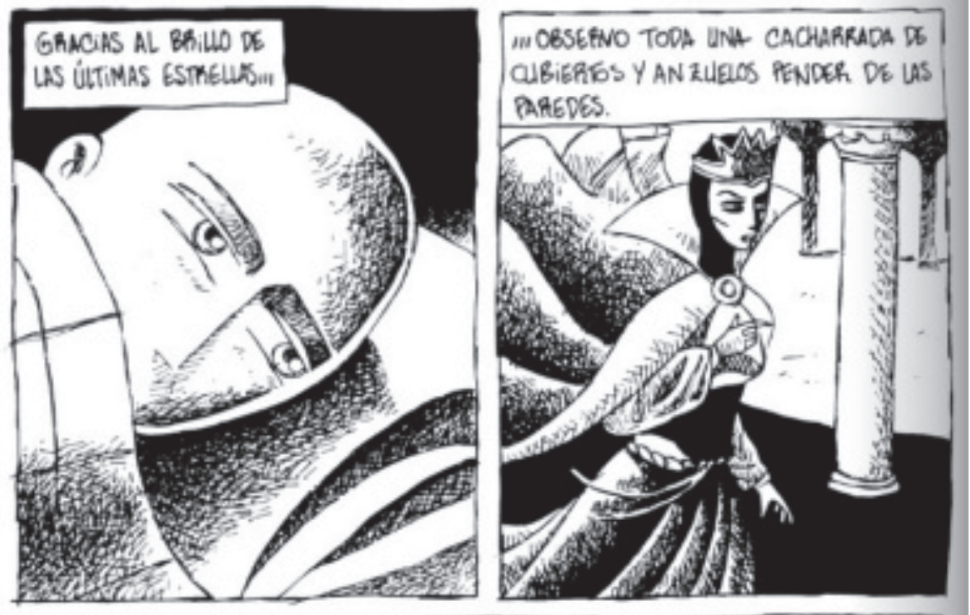

Figura 1. El Martín Pescador, p. 50.

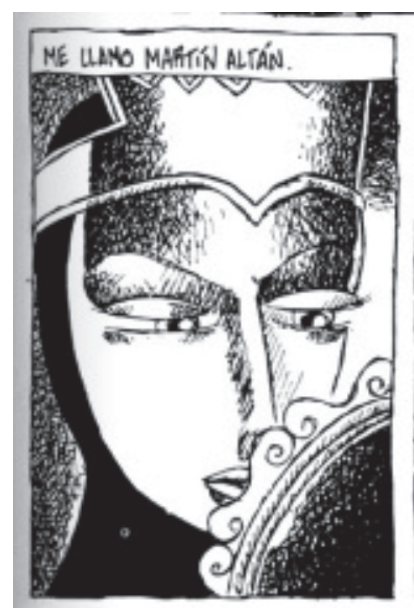

Figura 2. El Martín Pescador, p. 51.

recuerdos y de su identidad lo que le hace sentir como «un reflejo sólo capaz de devolver la superficie de algún estanque podrido» (91). George Novack, describe las fuerzas políticas y económicas que gobiernan el destino de los países capitalistas como «alien powers» y tanto en éstos como en los países comunistas, el ciudadano medio parece no tener ningún control sobre la situación:

Despite the great advances in science, technology, industry, public health and other fields made possible by their revolutions, workers and peasants, students and intellectuals keenly resent their lack of control over the government and 
the administration of the economy.... Despite the official propaganda that they have at least become masters of their own destinies, the people know that the powers of decision in the most vital affairs are exercised, not by them, but by bureaucratic caliphs (2002: 2).

Martín encarna ese ciudadano medio que frente al abrumador poder alienante de las fuerzas políticas y económicas observa con impotencia el secuestro de su destino y de su identidad.

Todo el entorno del político está compuesto de espejos que devuelven imágenes negativas a Martín. Su alienación comienza al verse reflejado en «algún estanque podrido» (91), al vender sus recuerdos y traicionarse. Martín y Martín Altán se transforman en imágenes especulares el uno del otro al compartir recuerdos de infancia. Y el alter ego de Altán, la madrastra de Blancanieves, es un ser malvado que se mira al espejo para matar. El espejo es la expresión gráfica de la alienación de Martín.

\section{LAS MATEMÁTICAS, EXPRESIÓN DE LA CARENCIA ALIENANTE}

Como hemos visto, Lacan contempla dos componentes de la alienación. Por una parte, la imposibilidad de identificación con la imagen de uno mismo y por otra la carencia: el niño que toma conciencia de que no vive en perfecta sincronía con el mundo y con la madre como extensión corporal. Lacan, en «El sujeto y el otro: la alienación» (2006), explica este segundo aspecto a través de diagramas de Venn y estos aparecen en el cómic en dos ocasiones, primero en una exposición matemática que visitan Martín y su amiga Arearea y después en la carta de despedida de Arearea.

En la primera viñeta (Fig. 3) se muestra A-B, uno de los diagramas utilizados por Lacan y que aparece en la carta de despedida. Lacan toma A como Sujeto y B como el Otro. La alienación se produce cuando el Sujeto queda desposeído del Otro (A-B) y por tanto castrado o el Otro queda también castrado desposeído del Sujeto. En la segunda viñeta (Fig. 4), A $\cap$ B, el conjunto A y el conjunto B pueden tener la parte central en común o ser el único espacio que no comparten. Para Lacan, este último caso representaría un tipo de disyuntiva que se expresa en el término latino vel y que está presente en enunciados como «la bolsa o la vida». Éste implica, por una parte, elegir la bolsa y perder tanto la bolsa como la vida, o por otra, elegir la vida y vivirla en la carencia de la bolsa. La intersección o «a» según lo denomina Lacan, será aquello que les falta a ambos, lo que los castra. La castración, entonces, recae tanto 


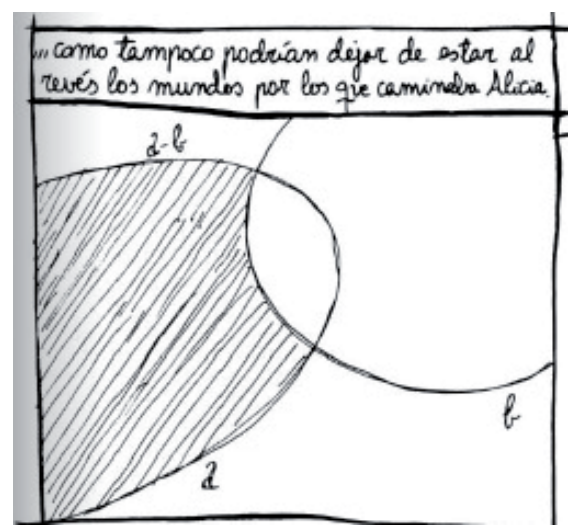

Figura 3. Diagrama de A-B que aparece en El Martín Pescador, p. 185.

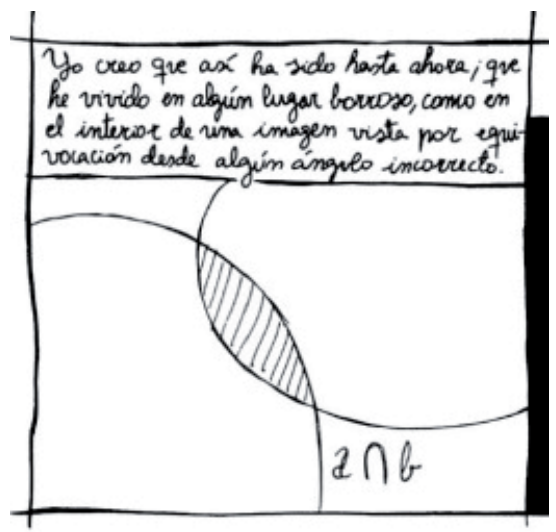

Figura 4. Diagrama de A $\cap$ B. El Martín Pescador, p. 184.

sobre el campo del sujeto, como sobre el campo del Otro, que sería el espacio intermedio $(\mathrm{A} \cap \mathrm{B})$.

En la exposición matemática del cómic, el resto de cuadros son expresiones de figuras y sus dobles o reflejos en puntos específicos ( $a a^{\prime}, b^{\prime} b^{\prime}$, etc) así como referencias al lógico Lewis Carroll, quien fue contemporáneo de Venn y amplió los diagramas de éste y su antecesor, Euler. Por ejemplo, la segunda viñeta (Fig. 5) muestra los círculos de Euler que él desarrolló añadiendo el Universal y que se plantea en la formulación del «no cumpleaños». ${ }^{4}$

4. Dado que Arearea es una suerte de Alicia a través del espejo, la exposición de diagramas matemáticos a la que lleva a Martín es también una referencia a Lewis Carroll. Por ejemplo, junto al diagrama de la disyuntiva se repiten los círculos de Euler: 

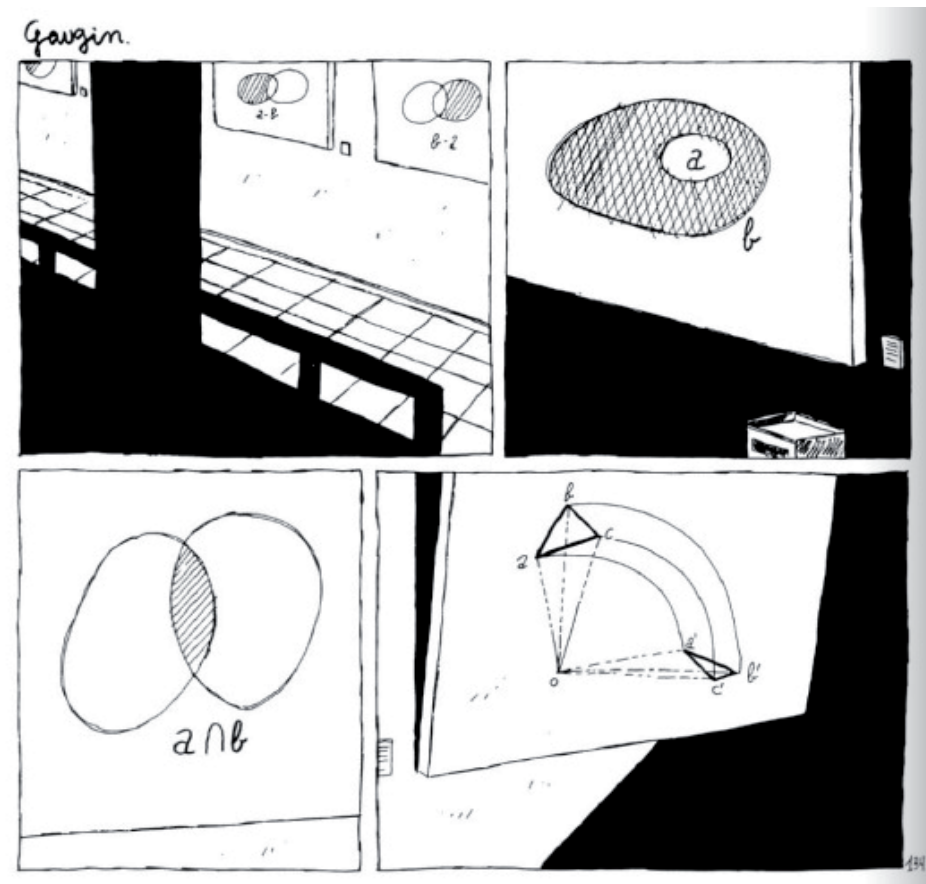

Figura 5. Diagramas que aparecen en la exposición matemática. En la primera viñeta A-B y B-A. En la segunda, los círculos de Euler. En la tercera A^B. En la cuarta, la proyección de una figura geométrica. El Martín Pescador, p. 134.

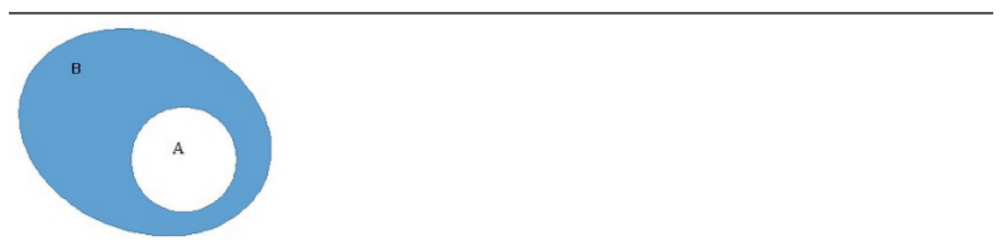

Los círculos de Euler y los diagramas de Venn fueron ampliados por Carroll. En Alicia a través del espejo Humpty Dumpty discute el no-cumpleaños con la protagonista, que constituye el dilema de pertenecer y se representa con un diagrama de Luetich:

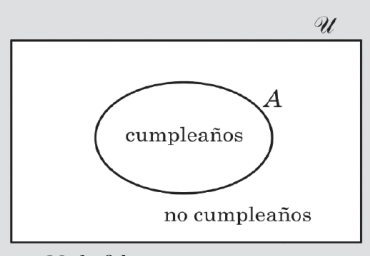

29 de febrero

A diferencia del de Euler, Carroll incluye U o conjunto universal que tiene las propiedades de un conjunto complementario. 
Es posible que la exposición solo sea una referencia a Lewis Carroll o al mundo de las matemáticas como otra forma de reflejo de lo conocido, ampliando así la diversidad de espejos que pueblan este cómic, pero también guardan una estrecha relación con el tema de la alienación que recorre la obra.

\section{INFANCIA}

Martín es acompañado en su periplo por Arearea, quien trabaja para Altán pero tampoco se identifica con este entorno. Ella es una niña que en vez de jugar es un juguete del político, al que «le gusta ver[la] leer, jugar...a veces la peina» (85). Uno de los libros que Arearea lee para Altán es la obra de Martín y decide conocerle porque, según explica «en cierto modo usted y yo hemos vivido infancias similares [donde] también hubo espejos y muchos» (77-78). Efectivamente, en la de Martín hay dos pueblos que se reflejan como en un espejo, uno en el fondo de un lago y otro idéntico construido en la orilla. En la de Arearea, el pueblo estaba sumergido en un valle cuyas montañas no dejaban pasar el sol, problema que se solucionó instalando espejos alrededor que reflejaran la luz. Arearea se mira en Martín como en un espejo y se convierte en su aliada porque él proporciona un camino hacia la desalienación. ${ }^{5}$

La infancia es uno de los temas recurrentes de la obra de Durán. En ella se desarrolla la imaginación y ésta «es la llave que abre la puerta, el prisma por el que ha de mirarse cada escena que sucede y se desarrolla durante la vida» (Durán, 2012a). Arearea, en su carta de despedida, le plantea a Martín «He sentido que el mundo en el que he vivido desde que ingresé en la Agencia es, tan solo, un reflejo grotesco de algún otro mundo más amable» (183) y regresa al lugar donde pasó su niñez, lugar desde el que puede «mirar cada escena» y comprender que el entorno alienante del político es el verdadero mundo al revés. La travesía de Arearea y de Martín es un nexo con la infancia, es lanzar anzuelos hacia el fondo de sus recuerdos.

5. Arearea opera como la auxiliar del héroe Martín. José Manuel Pedrosa explica la lógica del ayudante a través de la teoría sobre el don de Marcel Mauss. Toda alianza humana se basa en un intercambio de dones. El héroe posee algo que puede ser valioso para aquellos que se encuentra en su camino y ellos contribuyen al éxito del héroe. Arearea necesita escapar de la Agencia y volver a su pueblo. Ella encuentra en Martín su vía de escape y a cambio le puede acompañar por el inframundo en el que se ha sumergido. El intercambio de dones asegura la alianza de ambos. 
Dado que Martín y Arearea se encuentran alienados, carentes de infancia, emprenden una búsqueda metafórica. Este camino se conforma como un laberinto por la ciudad y en él se desarrolla una relación de alianza entre el héroe, Martín, y su auxiliar, Arearea. La obra de Luis Durán es rica en arquetipos con resonancias míticas. ${ }^{6}$

José Manuel Pedrosa estudia la literatura folclórica y las funciones de los mismos. En su estudio antropológico sobre «La lógica de lo heroico» afirma que una de las condiciones que ha de cumplir cualquier tipo de héroe es ser capaz de atravesar un lugar muy estrecho victoriosamente. Para Pedrosa, «la capacidad penetradora del héroe debe acreditarse tanto en el sentido de entrada como en el de salida del tubo. En ningún caso puede quedarse el héroe dentro. Quedarse en el interior del tubo equivale a la muerte, supone el devoramiento por las fuerzas contrarias, aplastantes, que pueden engullir a cualquier tipo de persona que no sea el héroe» (2003: 52). El reto de Martín y Arearea es el de salir a tiempo de no quedar digeridos dentro de la intricada red de tubos y pasadizos que lo conforman.

Los paseos que hacen juntos también transforman no lugares en espacios significativos de intercambio social. Pero estos paseos por el mundo de la vigilia solo son un reflejo de otros tres laberintos metafóricos por el inframundo, el mundo del revés y el mundo onírico. Cada uno de ellos es el anverso de un espejo: el inframundo es el anverso del de Altán, el mundo del revés del de Arearea y el mundo onírico el de Tutumukuku. En esta sección se realiza una aproximación analítica a cada uno de ellos.

\section{LA CIUDAD: EL LABERINTO DE LA VIGILIA}

Los desplazamientos de cada personaje por la ciudad dibujan una suerte de laberinto que estructura la obra. La mayoría de ellos son caminantes, que recorren las calles y el interior de los edificios trazando sendas al principio tangenciales y después cruzadas. En este haz de trayectorias, cada uno parte de puntos diferentes. El primero en aparecer es el misterioso vecino que solo se mueve en círculos dentro de su casa. Después Martín y su vecino se desplazan por el edificio compartiendo itinerario. El siguiente personaje es Aurelia,

6. Como él mismo afirma «mis personajes (...) están en permanente búsqueda. También dejan claro que no conocen otra ruta en esa búsqueda que el intento de recuperar esas alas amputadas (...) las de la imaginación, la infancia, los arquetipos...» (2012b). 
que camina por las calles de la ajetreada ciudad para visitar a un enfermo terminal. Y por último Arearea es presentada metonímicamente a través de sus piernas, mientras camina por un museo. ${ }^{7}$ Son personajes en movimiento que dibujan múltiples itinerarios y desvían la travesía del lector de un punto a otro.

Además de los caminos que puedan trazar unos y otros, la figura formal del laberinto se expresa gráficamente de varias maneras. Por una parte, el propio Martín y otros personajes aparecen atrapados en un laberinto de espejos mientras sueñan. Esta figura será analizada en la sección dedicada al laberinto onírico. Otra expresión formal es una sutil manera de cerrar los capítulos a través de viñetas blancas o negras. Por ejemplo, el capítulo titulado «Con la forma de un ser vivo», se cierra con una viñeta negra tras presentar a los agentes de Altán espiando a Martín (Fig. 6). El siguiente capítulo, titulado «Encendiendo una vela donde se apaga otra», se cierra con otra blanca porque sigue a dos viñetas en que Tutumukuku enciende una vela (Fig. 7). Las viñetas finales negras se suceden a medida que Martín se implica en la biografía, es decir, a medida que se hunde más en un «estanque podrido» mientras las viñetas blancas cierran los capítulos una vez que Martín comunica a Altán su decisión

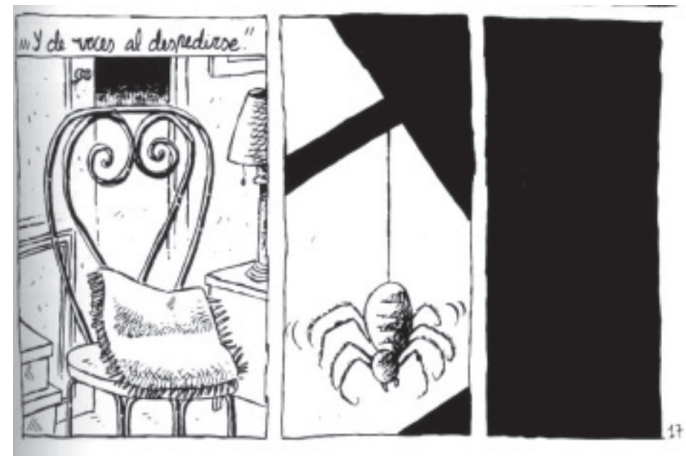

Figura 6. Capítulo que acaba en viñeta negra. El Martín Pescador, p. 17.

7. Existe una excepción y es «la mosca humana», un personaje que aparece sentado fuera de su caravana sin desplazarse a ninguna parte. Es significativo que sea incluido aquí ya que es el único personaje apartado de la ciudad, que pertenece a otro entorno y que no guarda conexión con ninguno de los demás. Sin embargo, como Martín y Arearea, también él es un personaje alienado, que añora la identidad de «Mosca humana» adoptada en su juventud como luchador. Probablemente esta profesión sea un guiño al personaje original, creado por Bill Mantlo y Alt Milgrom en 1977 para Marvel cómics y que se basó en la vida del acróbata Rick Rojatt. Al final del cómic, él también recibe la visita de Tutu en sueños y éste le anima a volver a serlo. Al día siguiente, recibe a Martín vestido con su antiguo traje mientras prepara una barbacoa, orgulloso de volver a sentirse como el personaje que creó. Él es la encarnación del drama de la alienación que el género de superhéroes en el cómic ha desarrollado como ningún otro medio. 
de abandonar el encargo. Son una expresión formal que indica el desarrollo de la travesía metafórica del protagonista. ${ }^{8}$

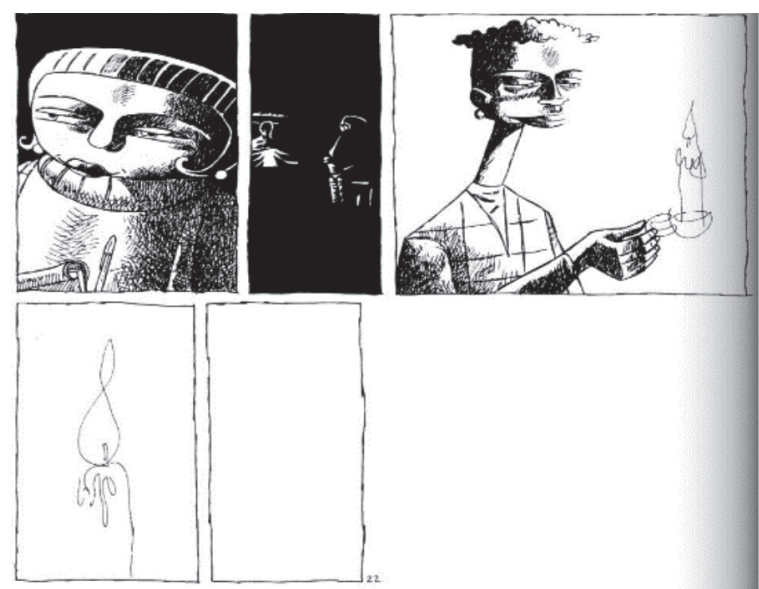

Figura 7. Capítulo que acaba en viñeta blanca. El Martín Pescador, p. 22.

INFRAMUNDO: BAJADA A LOS INFIERNOS

Los itinerarios de Martín se ven alterados al recibir el encargo de Altán. El protagonista nota que unos hombres le siguen desde su lugar de trabajo hasta su casa. Continúa su rutina hasta que un día interrumpen su clase, lo meten en un coche y le llevan a ver al político. Le escoltan hasta su despacho y de aquí se desplazan a un evento publicitario encerrados en un coche otra vez. Esta forma de desplazarse, aprisionado entre cuatro paredes, supone tanto una transformación como el contacto con el submundo. En Ulysses de James Joyce, el capítulo dedicado al funeral del padre de Leopold Bloom tanto el cambio en el de modo de transporte - desplazarse en carruaje en lugar de ir a pie- como la visita al cementerio conlleva una forma de «incubación» que refiere tanto a los úteros como a los ataúdes. ${ }^{9}$ Para José Manuel Pedrosa, el encierro en toda forma de ficción tiene connotaciones heroicas: «es muy común que [los héroes] pasen o que hagan pasar, a ellos mismos o a otras personas u objetos, por espacios sumamente estrechos. Los límites y los espacios que quedan entre rocas que chocan, puertas que se abren y se cierran, o aplas-

8. También sería interesante interpretar estas viñetas como espejos: negros cuando no hay posibilidad de identificación o reflejo y blancos cuando sirven como umbral o se abren a la mirada del otro.

9. James Joyce definió la técnica utilizada para este capítulo como «incubismo» por dos razones. La primera es que un íncubo es una figura demoníaca que produce pesadillas y este capítulo está relacionado con la muerte. La segunda es que el paso por los espacios estrechos y lóbregos simula un ataúd pero también un útero. 
tantes mandíbulas animales, pueden ser considerados como diferentes especies de tubos de amenazante estrechez que sólo el héroe, con sus potencias sobrehumanas, es capaz de atravesar» (2003: 2).

El encierro de Martín y de Leopold Bloom en sendos vehículos es una «incubación» que lo acerca tanto a la muerte como al estado de gestación. Martín comienza a gestarse como héroe de su propia historia al atravesar las calles encerrado en el coche de Altán. Ésta es solo la entrada al submundo: encontrar la salida a través del laberinto de reflejos es lo que definirá su naturaleza heroica.

El laberinto de Arearea: Alicia a través del espejo

El laberinto de Arearea está al otro lado del espejo de la aburrida vida de Martín y constituye un divertido mundo de estrafalarios personajes. Ella desvía continuamente los itinerarios de Martín, obligándole a romper con sus rutinas y arrojando luz sobre los oscuros tubos cerrados que componen el entorno de Altán, el político.

Arearea es el resplandor, el faro que alumbra el camino. En su primera aparición, ella se encuentra en un museo observando el cuadro que lleva su nombre, el Arearea de Gauguin, palabra haitiana que significa pasatiempo o entretenimiento alegre. Tras disfrutar de la exposición va al aseo y se cambia los zapatos por unos nuevos con girasoles que acaba de comprar. El símbolo del girasol se repite a lo largo del cómic: el abuelo de Martín es el Sr. Tornasol, Martín tiene girasoles en su delantal y la Mosca Humana usa una toalla con impresiones de girasoles. Todos ellos llaman la atención de Arearea, cuyos pasos buscan el sol como los heliotropos de sus zapatos.

Arearea es una suerte de Alicia Lidell que quiere volver a su casa. La relación entre ambas se hace evidente la primera vez que se introduce la figura de Alicia mientras Arearea lee el primer capítulo que Martín escribe para la biografía falsa de Altán. Este relato comienza describiendo el pueblo y el oficio del abuelo como pescador. Mientras esperan que los peces piquen, el abuelo le explica que su pueblo es una copia exacta del que hay sepultado bajo el agua y que esto les llevó «a construir otro pueblo, junto a la orilla, exactamente igual que el que abandonábamos» (58). Estas palabras se presentan sobre una viñeta de fondo negro que sirve de transición para una serie de seis viñetas que operan como digresión y, sin texto, muestran a Alicia en el momento en que descubre que la superficie del espejo en que se mira es acuosa, la puede atravesar con la mano, e introduce la cabeza. Lo que ve se muestra a toda página: es el pueblo sumergido de Martín acompañado por las palabras 
«Mientras los cebos descendían lentamente hasta el corazón del pantano» (Fig. 8). Alicia es Arearea asomándose a la infancia de Martín. Arearea, sumergida en el mundo de tinieblas del político, observa esos cebos y Martín se convierte en el pescador que la puede ayudar a salir de él. Por eso le acompaña en su periplo, le enseña a nadar en las turbulentas aguas del mundo de Altán, y cuando él sale a flote ella encuentra el camino a casa.

Arearea atraviesa el espejo como la Alicia de Lewis Carroll y guía a

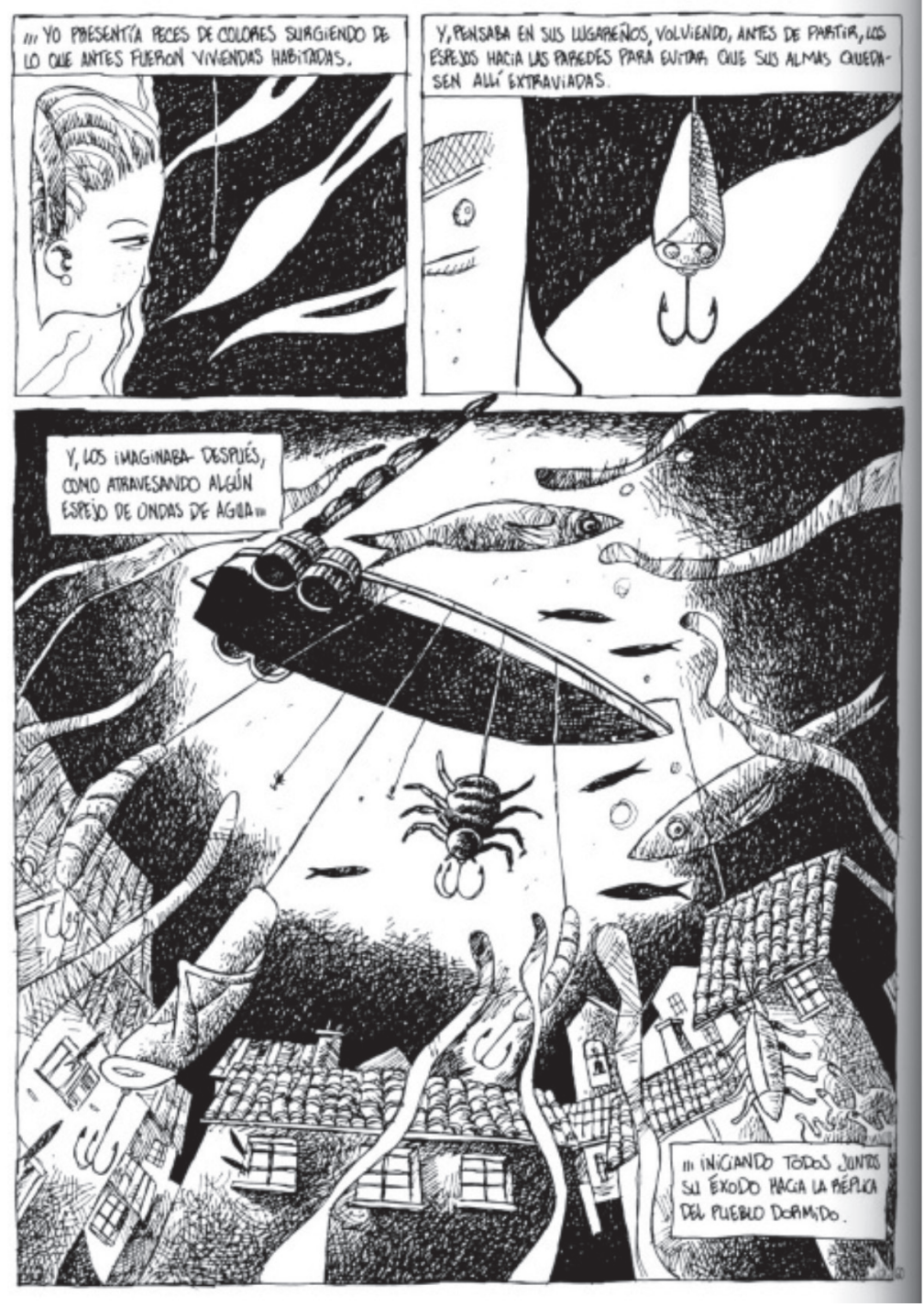

Figura 8. Arearea como Alicia. El Martín Pescador, p. 59. 
Martín por su mundo, el mundo del revés, presentando curiosos personajes que ofrecen diferentes reflexiones sobre la función de los espejos y ofreciendo claves para encontrar la salida al laberinto de la alienación. Uno de esos lugares es la exposición de cuadros matemáticos ya comentada. Otro es la casa del vecino, quien escribe una enciclopedia llamada «Especulum Mundi» o espejo del mundo. En ella anota los datos más triviales de la existencia como « 8 '45: Una araña se desliza, como una sombra chinesca, por la pared de la habitación» para crear «el espejo en el que se refleja todo lo que se ha hecho en el mundo desde su conocimiento hasta su fin» (130). El misterioso vecino parece inspirado por los gemelos Tweedle de Alicia a través del espejo, ya que su percepción de la existencia y de los espejos enfatiza la copia. En la obra de Carroll, los gemelos son copias especulares el uno del otro o enantiomorfos. Cuando llega Alicia, ellos están de pie al lado con un brazo por el hombro del otro. Luego enseñan a Alicia cómo saludar a alguien y al darse la mano el uno al otro conforman un reflejo perfecto. Su naturaleza especular se enfatiza por su palabra favorita: «Contrariwise». También en este capítulo aparece el rey de corazones soñando con Alicia y ésta, a su vez, soñando con él, lo que refuerza el carácter especular del episodio: Alicia sueña con el rey, quien sueña con Alicia, quien sueña con el Rey, etc. Los gemelos Tweedle le dicen a Alicia que ella no es más que «a sort of thing» en el sueño del rey, una referencia a la filosofía de George Berkeley para quién lo físico no es más que "A sort of thing» a los ojos de Dios. ${ }^{10}$ Tanto la imagen enantiomorfa que devuelve el espejo como la incertidumbre existencial de este capítulo de Alicia forman parte del encuentro con el vecino en el cómic de Luis Durán. El vecino copia la realidad como los espejos devuelven copias de la misma.

En general, Arearea es un catalizador de encuentros y de esta manera transforma meras zonas de tránsito en espacios de intercambio social. Como se explicó anteriormente, todos los personajes trazan itinerarios por la ciudad y la narración sigue sus pasos, dotando a la obra de una estructura laberíntica. Todos son caminantes, habitantes de la ciudad moderna que, como Leopold Bloom, surcan sus calles y travesías ajenos a los numerosos estímulos externos mientras pasan las horas en el tiempo lento de lo cotidiano, de lo insignificante. ${ }^{11}$ Y como el sujeto anónimo de la sobremodernidad descrita por Marc Augé, pasean por no lugares, espacios donde la interacción social se dificulta.

10. Véase la interesante interpretación de Martin Gardner de este pasaje en Annotated Alice: The Definitive Edition.

11. Para un estudio de lo cotidiano y el aburrimiento en la novela gráfica, véase el libro de Greice Schneider What Happens when Nothing Happens. 
Ellos deambulan con cara seria por las calles, esperan el metro, hacen cola en los museos y en definitiva atraviesan zonas de tránsito sin interacción. Los no lugares están sujetos a una fuerte normativa social, que mantiene el orden y las reglas del comportamiento civilizado. En ellos, la identidad depende de un carné, tarjeta de crédito o documento oficial por oposición a un lugar donde esa identidad viene dada por resonancias personales o afectivas. Los protagonistas de esta historia son habitantes de la sobremodernidad pero Arearea cataliza los intercambios sociales y conecta los caminos del extraño vecino, de Martín, y de otros personajes que de otra manera hubieran seguido avanzando de manera tangencial. En el laberinto de la ciudad, las desviaciones de Arearea operan como dones que ayudan al héroe a encontrar la salida. Su amistad se forja en el camino, transformando el mero desplazamiento en travesía simbólica. De esta forma, lo que eran no lugares, meras calles de tránsito, se convierte en espacios de conocimiento.

\section{EL LABERINTO ONÍRICO: EL ANVERSO DE LA VIGILIA}

Martín desciende a los infiernos a través de tubos laberínticos. Arearea se alía con él y caminan juntos por el mundo del revés. Pero ninguno de los dos tiene la clave para encontrar la salida hasta que conocen a Tutumukuku y a Aurelia, quienes les invitan al otro lado del espejo de la vigilia, al mundo de los sueños. En El Martín pescador, Tutumukuku opera como psicopompo por el inframundo para guiarlo hasta la salida.

En el reino de los sueños, tanto Martín como después Tutu y su amiga Aurelia aparecen perdidos en laberintos de espejos (Figs. 9, 10 y 11).

El laberinto es la expresión gráfica de la confusión y desasosiego que experimentaron cada uno de ellos en diferentes circunstancias, la forma que toma la búsqueda vital. En el sueño en que Martín aparece dentro de un laberinto, éste quebranta las normas de la razón y atraviesa uno de los espejos que conforman sus paredes. Del otro lado encuentra a Tutu y es testigo de la destrucción metafórica de Altán. Simbólicamente, este sueño le ofrece una salida a su coyuntura personal: no dar por sentadas las circunstancias que parecen tan invariables y naturales como la dureza y las propiedades físicas de un espejo. Martín finalmente se da cuenta de que puede oponerse a Altán y sentirse libre.

Cuando Martín despierta, acude a una cena con el político, donde le comunica su decisión de abandonar el encargo. La cena opera como una última bajada al inframundo en la que Martín, como una suerte de Perséfone en el Hades, evita probar bocado para no regresar jamás. Le sirven cochinillo, 


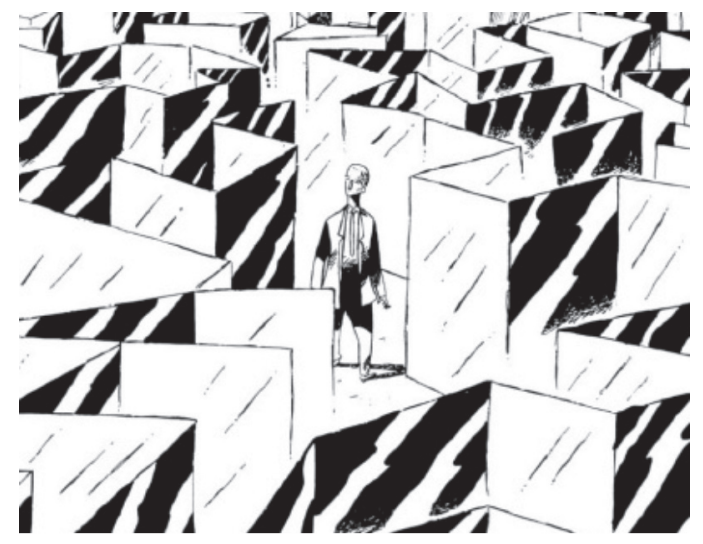

Figura 9. Martín en su laberinto. El Martín Pescador, p. 139.

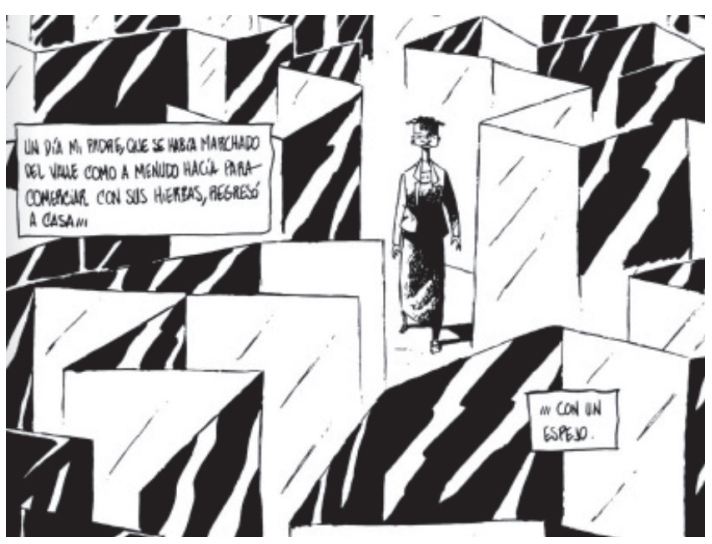

Figura 10. Tutu en su laberinto. El Martín Pescador, p. 163.

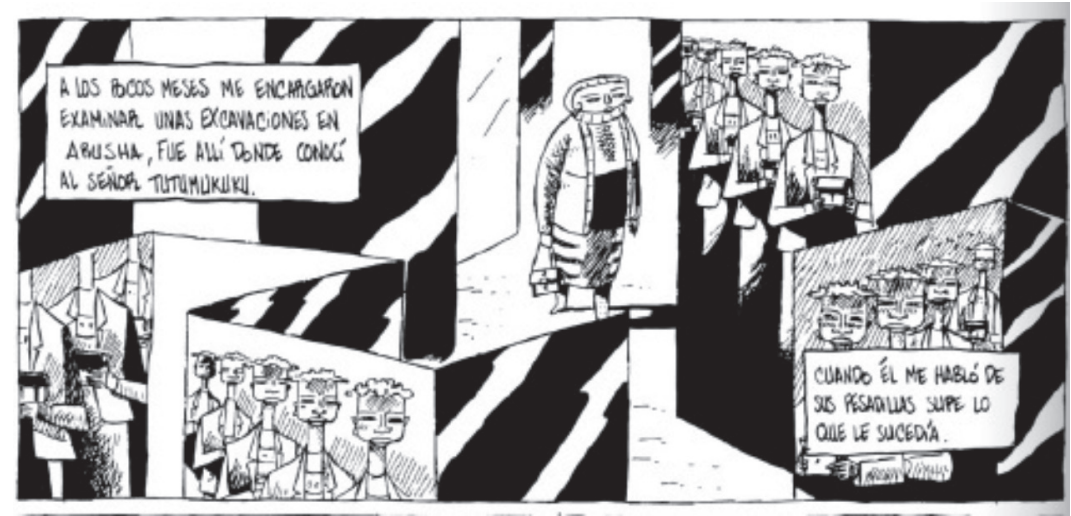

Figura 11. Aurelia en su laberinto. El Martín Pescador, p. 170. 

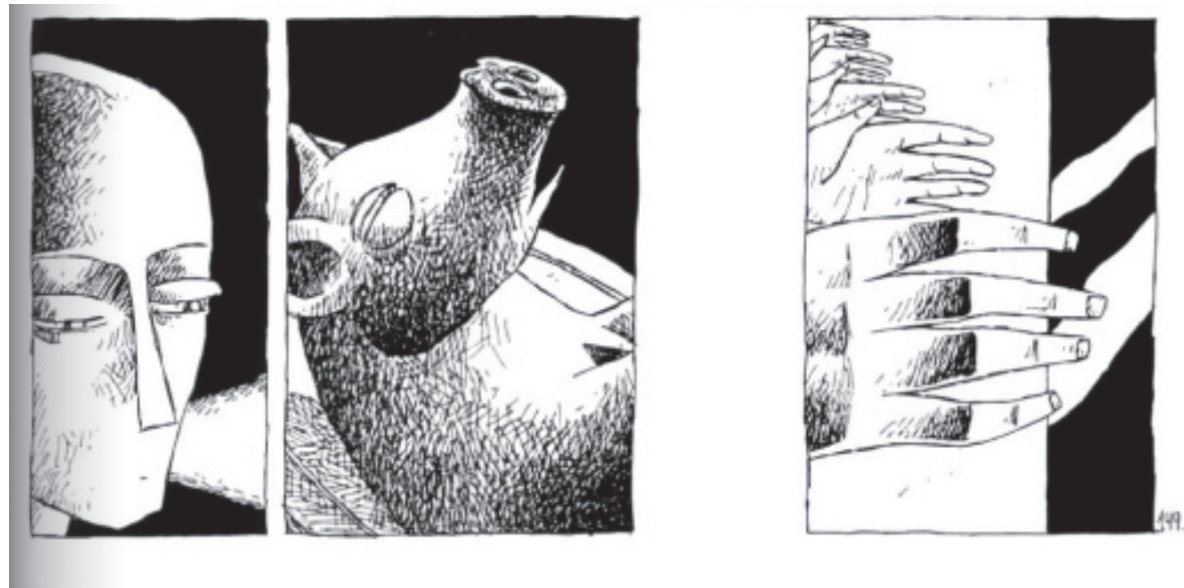

Figura 12. Martín observa la comida y evoca su sueño en el laberinto. El Martín Pescador, p. 149.

pero mira el animal muerto con suspicacia (Fig. 12). El cochinillo, la cena, la opulencia, la bienvenida de Altán, todo es un potlatch que establece un intercambio de dones aplazado entre Martín y el político. ${ }^{12}$ Si Martín acepta la hospitalidad de su anfitrión, quedará en deuda y deberá pagarla con su trabajo. En la siguiente viñeta, Martín le comunica que «no pued[e] escribir su libro» (150), se levanta, se marcha, y la última viñeta es blanca y vacía, señalando la luz al final del túnel. Durante la cena se intercala una viñeta que hace alusión al laberinto del capítulo anterior, con la mano de Martín reflejada hasta el infinito por los miles de espejos antes de acercarse a su superficie y comprobar que la podía atravesar. La labor de Tutu como psicopompo, la materialización de los temores del protagonista en forma de laberinto, en definitiva, el mundo onírico, devuelven una imagen triunfante a Martín de sí mismo. En el espejo de los sueños, éste encuentra el héroe que necesita ser, el espejo en que mirarse, su identidad y por tanto la salida del laberinto.

12. Marcel Mauss explica que a través de los festines, banquetes y en definitiva una generosa distribución de alimentos y bienes en teoría gratuitas se hace alarde de la superioridad del anfitrión o tribu anfitriona al tiempo que se establece una deuda de los invitados hacia los donadores: «Potlatch significa esencialmente «alimentar», «consumir». Estas tribus, muy ricas, que viven en las islas, en la costa o entre las Montañas Rocosas y la costa, pasan su invierno en una fiesta perpetua: banquetes, ferias y mercados que, al mismo tiempo, constituyen la solemne reunión de la tribu» (2009: 76-77) y concluye «Hemos detectado este tipo de formas intermedias en el mundo indoeuropeo antiguo, en particular entre los tracios. Este tipo de derecho y de economía contiene diversos temas, reglas e ideas. Evidentemente, el más importante de esos mecanismos espirituales es aquel que obliga a devolver el presente recibido» (2009: 79). 
LO ONÍRICO COMO ORIGEN DE LO FANTÁSTICO

Lo onírico se establece así como espacio curativo. Martín necesita recuperar su identidad cuando todo se ha vuelto del revés: los políticos que promueven confianza son sospechosos, las niñas se comportan como adultos, sus recuerdos son recuerdos de otro y los espejos no reflejan sino que alteran la percepción o actúan de umbral. En este sinsentido, el mundo de la vigilia, el orden apolíneo es secundario y lo onírico, lo ilógico y lo dionisíaco es donde se pueden hallar respuestas.

Esta es una constante en la obra de Durán. Por ejemplo, en Una colmena en construcción, también explora la relación entre vigilia y sueño:

En este libro, Jacinto, uno de los personajes ve este mundo que habitamos como una copia, algo tosca y aún sin pulir, de ese otro mundo que se nos representa por medios oníricos. De hecho, el personaje lleva 40 años intentando superponer ambos mundos, el real y el onírico y que estos coincidan a la perfección. Por eso construye su catedral. El señor Don Pipo tiene una llave que solo abre puertas soñadas. El mundo onírico tiene en este libro un papel referencial en unos casos, sincrónico en otros, poético siempre (Durán, 2014).

Asimismo, en su obra más reciente, Orlando y el juego, recupera el personaje de Tutu y lo sitúa en diferentes planos oníricos. El sueño en la obra de Durán es siempre la existencia verdadera de la cual la vigilia solo es una copia descolorida.

Para Jorge Luis Borges, toda ficción es una forma de sueño y toda existencia es un emocionante laberinto en el que nunca se sabe lo que hay al final de cada giro o esquina: «El camino es fatal como la flecha / Pero en las grietas está Dios, que acecha» (OC, 3: 153). En las grietas asoma lo inconcebible, lo maravilloso, lo que escapa a la razón. Las grietas en El Martín Pescador son aquellas instancias en que lo onírico invade lo real.

Al alterar las normas de los sueños, al dejar de ser caóticos y simbólicos y los personajes se comunican con el soñador como lo harían con él en la vigilia, se produce lo fantástico. La aparición de Tutu y de Aurelia en el salón de Martín establece un diálogo entre ambas ontologías que cuestiona el mundo real. Como afirma Tzvetan Todorov (1995), desde La Metamorfosis de Kafka, lo fantástico ya no enfrenta lo real y lo irreal sino dos realidades distintas. Nancy H. Traill (Lomeña, 2013), desarrolla la teoría de Todorov y clasifica distintas relaciones entre lo real y lo fantástico, define el estado en que lo sobrenatural irrumpe desde lo natural (el caso de la narrativa kafkiana) como lo fantástico 
paranormal. La ONG de Tutu y Aurelia por la que salvan a la gente a través de los sueños describe precisamente este modo: cuando lo sobrenatural toma el control de lo natural desde la propia lógica de lo real. Los sueños que dejan de comportarse de manera caótica para ofrecer un discurso coherente, una explicación racional en el salón de la casa, y que además tienen consecuencias en el comportamiento de los personajes una vez despiertos.

Así se conforma uno de esos laberintos borgianos en los que el que sueña es soñado y viceversa, multiplicando dimensiones como los espejos enfrentados multiplican las imágenes ad infinitum. En este punto, Arearea plantea la cuestión clave que toda la obra pretende responder: «¿Se imagina, señor Martín, que no fuéramos personas sino solo...solo sus reflejos?» (88). El espejo puede ser una forma de heliotropo que arroja luz donde no la hay, como Arearea en la vida de Martín. Pero la esencia del espejo es yuxtaponer dos realidades opuestas, como lo fantástico abre la puerta al diálogo entre dos ontologías. Si la copia o el reflejo es tan real como el original, se subvierte la jerarquía entre ambos órdenes y se produce una dislocación del orden de lo real.

Lo real no solo queda transformado, sino que su validez se pone en entredicho. Para David Roas, el elemento fantástico casi siempre altera inevitablemente la lógica de lo no fantástico y «su dimensión transgresora va inevitablemente más allá de lo textual: su objetivo es siempre cuestionar los códigos que hemos diseñado para interpretar y representar lo real» (2009: 108). Por ello la «presencia imposible problematiza el precario orden o desorden en el que fingimos vivir más o menos tranquilos» (2009: 116). En El Martín Pescador, Arearea afirma que el mundo supuestamente real es el que está al revés: «yo creo que he vivido en algún lugar borroso, como en el interior de una imagen vista por equivocación desde algún ángulo incorrecto» (184) e insta a Martín a transformarse y percibir lo que le rodea de otra manera. Efectivamente, la subversión de la lógica de los sueños supone una alteración en el modo de percibir la vigilia que altera la naturaleza y la experiencia de los personajes.

\section{EL SURREALISMO COMO LENGUAJE}

El mundo onírico y lo fantástico como grieta por la que se cuela y lo modifica, provocan un cambio sin retorno y al final de la obra, no solo los protagonistas sino varios personajes secundarios resultan transformados. Por ejemplo, el extraño vecino que dedica su vida a anotar datos de lo más insignificantes para crear una enciclopedia que sea «Espejo del Mundo» aparece 
feliz dibujando una flor. Arearea desea que «ese señor que lo anota todo, se dedique solo a recopilar cosas útiles» (184). Los propios personajes de la obra afirman que el «Espejo del mundo» no consiste en la copia, en la descripción detallada del entorno y los sucesos como los describiría un discurso realista, sino en la metáfora, en la imagen que no puede ser reducida al silogismo de la razón.

Para Roman Jakobson, el desarrollo de un discurso se alinea en torno a dos formas semánticas: un tema puede llevar a otro por similitud, utilizando la metáfora, o por contigüidad, con la metonimia. Con respecto a los sueños, él considera que la cuestión decisiva es si los símbolos y las secuencias temporales se basan en la contigüidad (lo que Freud llama «desplazamiento») o en la similitud (la «identificación» freudiana). En literatura, Jakobson encuentra dos maneras de narrar o de expresión artística: metonímica o metafórica: «The primacy of the metaphoric process in the literary schools of romanticism and symbolism has been repeatedly ackowledged, but it is still insufficiently realized that it is the predominance of metonymy which underlies and actually predetermines the so-called "realistic" trend, which belongs to an intermediary stage between the decline of romanticism and the rise of symbolism and is opposed to both» (2004: 77).

Esta misma predominancia alternativa entre ambos procesos se observa también en otras formas artísticas no verbales como el cine o la pintura: «A salient example from the history of painting is the manifestly metonymical orientation of cubism, where the object is transformed into a set of synecdoches; the surrealist painters responded with a patently metaphorical attitude» (2004: 77).

En El Martín pescador, el predominio de lo onírico es el predominio de la metáfora. En el primer sueño donde Tutumukuku consigue hablar a Martín le informa de que «nuestra comunicación se limita en estos momentos a asociaciones de ideas, emociones, imágenes...resumiendo...a símbolos» (116-117). La predominancia de los sueños en el cómic hace que esta gramática aparentemente caótica sea el lenguaje narrativo principal. La metáfora es lo que Martín necesitaba para contar su historia y su travesía por el mundo onírico facilita la liberación entre significante y significado del mismo modo en que imágenes y objetos aparentemente desvinculados establecen una relación semántica por contigüidad. Tutu exhorta a Martín a escribir: «Lo primero que ha de hacer usted cuando despierte es escribir los sueños que haya tenido durante la noche... así que tenga siempre un cuaderno a mano» (154). Escribir sus sueños es describir lo que narra el cómic así que contar su propia historia 
se convierte en una forma de recuperar su identidad. Martín aprende el lenguaje de lo fantástico para poder narrar sus vivencias.

La infancia es, según Lacan, el espacio en que se produce la primera forma de alienación: reconocerse en un espejo como otro y carecer de nexo con el mundo. Los protagonistas de El Martín Pescador sufren un proceso similar al ser despojados de sus recuerdos ante unas circunstancias opresivas. Sin embargo, en esta obra, la infancia es un lugar de curación porque alberga el potencial de lo fantástico. La laberíntica travesía que deben realizar Arearea y Martín hasta encontrarse a sí mismos es un viaje hacia el lago donde verse reflejados, donde saber quiénes son y donde echar sus anzuelos hacia el olvidado mundo de sus recuerdos. Para Luis Durán, el puente con los días de la niñez en la edad adulta es el espacio onírico. Los sueños son el resquicio de la metáfora, de la liberación entre significante y significado y por tanto de las normas de la razón.

Este artículo persigue el drama de la alienación como el hilo de Ariadna que permite explorar y conjugar dichos elementos. Esta doble vertiente de la alienación se expresa gráficamente en El Martín pescador a través de dos objetos simbólicos, el espejo y el laberinto. Martín, el protagonista, se aliena al asomarse como en un espejo al siniestro mundo del político Martín Altán y la carencia de una identidad, de un reflejo propio, es el impulso para recorrer el laberinto que lo lleva hasta el mundo fantástico de lo onírico. Los paseos que hacen juntos también transforman no lugares en espacios significativos de intercambio social. Pero estos paseos por el mundo de la vigilia solo son un reflejo de otros tres laberintos metafóricos por el inframundo, el mundo del revés y el mundo onírico. Cada uno de ellos es el anverso de un espejo: el inframundo es el anverso del de Altán, el mundo del revés del de Arearea y el mundo onírico el de Tutumukuku. Pero solo en el de los sueños se puede percibir «esa línea que separa el cielo de la tierra y que los alquimistas llamaron, con toda razón, el Sanctus Locus» (Durán, 2012a), la línea que divide la sinrazón de la cordura, la vigilia del sueño, lo fantástico del sinsentido.

\section{BiBLIOGRAFÍA}

Augé, Marc (1993): Los no lugares: espacios del anonimato, Gedisa, Barcelona. BRETON, André (1969): Manifiestos del surrealismo, Ediciones Guadarrama, Madrid. Borges, Jorge Luis (1989-1996): Obras Completas [OC], 4 vol., Emecé, Barcelona. Carroll, Lewis (2001): Annotated Alice: The Definitive Edition, Penguin Books (UK). 
Durán, Luis (2007): El Martín Pescador, Dolmen, Palma de Mallorca.

(2012a): «Luis Durán habla de la infancia y los sueños en el cómic Una colmena en construcción», entrevistado por Jesús Jiménez en rtve.es, disponible en <http:/ / www.rtve.es/noticias/20120604/luis-duran-habla-infancia-suenos-colmena-construccion/533243.shtml> [Acceso 15 Sep. 2016].

(2012b): «Charlando con Luis Durán, autor de Una colmena en construcción», entrevistado por Marisol Hernández en normaeditorial.com, 22 mayo, disponible en <http:/ / www.normaeditorial.com/blog/?p=4401> [Acceso 3 agosto 2016]. (2014): «Luis Durán: En Orlando y el Juego la realidad se derrite» entrevistado por Jesús Jiménez en rtve.es, disponible en <http://www.rtve.es/noticias/ 20140807/luis-duran-orlando-juego-realidad-se-derrite/988320.shtml> [Acceso 17 agosto 2016].

Freud, Sigmund (2004): «The Interpretation of Dreams», en Julie Rivkin y Michael Ryan (eds.), Literary Theory: An Anthology, $2^{\mathrm{a}}$ ed., Blackwell Publishing, Maiden, pp. 397-415.

JаковSON, Roman (2004): «Two Aspects of Language», en Julie Rivkin y Michael Ryan (eds.), Literary Theory: An Anthology, $2^{a}$ ed., Blackwell Publishing, Maiden, pp. 76-81.

LACAN, Jacques (1966): «Le stade du miroir comme fondateur de la fonction du Je, telle qu'elle nous est révélée, dans l'expérience psychanalytique», Écrits I, Seuil, París, pp. 89-97.

(2006): «El sujeto y el otro: la alienación», en El seminario de Jacques Lacan. Libro 11, Los cuatro conceptos fundamentales del psicoanálisis, Paidós, Buenos Aires, pp. 150-159

LomeÑA, Andrés (2013): «El espacio y lo fantástico en la novela desde la teoría de los mundos posibles: una revisión de las tipologías semánticas de la ficción», en Brumal. Revista de investigación sobre lo fantástico / Brumal. Research Journal on the Fantastic, vol. I, núm. 2, disponible en <http://revistes.uab.cat/brumal/article/view/v1-n2-lomena-cantos> [Acceso 3 agosto 2016]. <http://dx.doi. org $/ 10.5565 / \mathrm{rev} /$ brumal.18>

MAuss, Marcel (2009): Ensayo sobre el don. Forma y función de intercambio en las sociedades arcaicas, Katz Editores, Buenos Aires.

Novack, George (2002): Understanding History, Resistance Books, Australia.

Pedrosa, José Manuel (2003): «La lógica de lo heroico: mito, épica, cuento, cine, deporte... (modelos narratológicos y teorías de la cultura)», en Mitos y Héroes, Centro Etnográfico Joaquín Díaz-MECD, Urueña, pp. 37-63.

RoAs, David (2009): «Lo fantástico como desestabilización de lo real. Elementos para una definición», en Teresa López-Pellisa y Fernando Ángel Moreno (eds.), Ensayos sobre ciencia ficción y literatura fantástica, Universidad Carlos III de Madrid, Madrid, pp. 94-120.

SCHNEIDER, Greice (2016): What Happens When Nothing Happens: Boredom and Everyday Life in Contemporary Comics (Studies in European Comics and Graphic Novels), Leuven University Press, Bélgica.

Todorov, Tzvetan (1995): Introducción a la literatura fantástica, Coyoacán, Ciudad de México. 